Минимальная потребность

в реанимационных

койках и дыхательном

оборудовании в учреждениях,

перепрофилированных

под лечение новой

коронавирусной инфекции COVID-19

\author{
Б.В. Силаев, В.И. Вечорко, Д.Н. Проценко, \\ О.В. Аверков, Е.Ю. Халикова
}

ГБУЗ «Городская клиническая больница № 15 имени

О.М. Филатова Департамента здравоохранения Москвы»,

Москва, Россия

Реферат

В статье рассмотрены вопросы потребности в реанимационных койках и аппаратах искусственной вентиляции легких (ИВЛ) в госпиталях, перепрофилированных под лечение пациентов с новой коронавирусной инфекцией. По данным анализа работы Городской клинической больницы № 15 имени О.М. Филатова, в условиях перепрофилирования под инфекционный госпиталь потребность в койках отделения реанимации составила не менее $12 \%$ от общего числа коек госпиталя. Обеспеченность аппаратами для проведения ИВЛ должна быть не менее 80 \% от всего числа коек отделения реанимации. Кроме того, необходимо предусмотреть возможность расширения коечного фонда до 30 \% от числа штатных коек.

Ключевые слова: новая коронавирусная инфекция, COVID-19, искусственная вентиляция легких, неинвазивная вентиляция, отделение реанимации, коечный фонд, востребованность коек, перепрофилирование госпиталя, инфекционный госпиталь

Для корреспонденции: Силаев Борислав Владимирович канд. мед. наук, заместитель главного врача ГБУз «Городская клиническая больница № 15 им. О.М. Филатова Департамента здравоохранения Москвы», Москва; доцент

\section{Minimum requirements for rescuit beds and respiratory equipment in institutions refined for treatment of the new coronavirus infection COVID-19. Article}

\author{
B.V. Silaev, V.I. Vechorko, D.N. Protsenko, \\ O.V. Averkov, E.Yu. Khalikova
}

City Clinical Hospital named after O.M. Filatov of the Moscow Department of Health, Moscow, Russia

Abstract

The article discusses the need for resuscitation beds and mechanical ventilation devices in hospitals redeveloped for the treatment of patients with new coronavirus infection. According to the analysis of the work of the City Clinical Hospital No. 15 named after O.M. Filatov, in the context of re-profiling into an infectious diseases hospital, the need for beds in the intensive care unit amounted to at least $12 \%$ of the total number of hospital beds. Provision of apparatus for mechanical ventilation of lungs (mechanical ventilation) should be at least $80 \%$ of the total number of beds in the intensive care unit. In addition, it is necessary to provide for the possibility of expanding the bed capacity to $30 \%$ of the number of regular beds.

Keywords: new coronavirus infection, COVID-19, mechanical ventilation, non-invasive ventilation, intensive care unit, bed management, need for beds, re-profiling of the hospital, infectious diseases hospital

$\otimes \quad$ For correspondence: Borislav V. Silaev — Deputy Chief Physician in Anesthesiology and Intensive Care, Municipal Clinical Hospital No.15 named after O.M. Filatov, Moscow Health Departament, Associate Professor of chair of anesthesiology and critical care at faculty of medicine of I.M. Sechenov First Moscow State Medical University, Moscow; e-mail: drsilaev@yandex.ru

¿ For citation: Silaev B.V., Vechorko V.I., Protsenko D.N., Averkov O.V., Khalikova E.Yu. Minimum requirements for 
кафедры анестезиологии и реаниматологии лечебного факультета ФГАОУ ВО Первый МГМУ им. И.М. Сеченова Минздрава России (Сеченовский Университет), Москва; e-mail: drsilaev@yandex.ru

ए Для цитирования: Силаев Б.В., Вечорко В.И., Проценко Д.Н., Аверков О.В., Халикова Е.Ю. Минимальная потребность в реанимационных койках и дыхательном оборудовании в учреждениях, перепрофилированных под лечение новой коронавирусной инфекции COVID-19. Вестник интенсивной терапии им. А.И. Салтанова. 2020;2:34-40.

๘ Поступила: 26.05.2020

․ Принята к печати: 02.06.2020 rescuit beds and respiratory equipment in institutions refined for treatment of the new coronavirus infection COVID-19. Article. Annals of Critical Care. 2020;2:34-40

$๘$ Received: 26.05 .2020

自 Accepted: 02.06.2020

\section{Введение}

В условиях пандемии новой коронавирусной инфекции COVID-19 актуальным является вопрос перепрофилирования многопрофильных медицинских организаций с целью создания специализированных, ориентированных на лечение пациентов инфекционного профиля, отвечающих требованиям инфекционного стационара. Имеющиеся на данный момент приказы, рекомендации и другие нормативные акты ориентированы главным образом на опыт зарубежных стран, ранее столкнувшихся с проблемой лечения пациентов в условиях пандемии. В связи с этим вопрос расчета потребности в реанимационных койках и дыхательном оборудовании с целью оказания высококвалифицированной медицинской помощи является актуальным. Согласно Приказам Минздрава РФ № 918н, 928н отделения реанимации и интенсивной терапии (ОРИТ) для больных острым инфарктом миокарда и нарушением мозгового кровообращения не оснащаются аппаратами ИВЛ на каждую реанимационную койку, в частности, ОРИТ для больных острым инфарктом миокарда оборудуются 1 аппаратом ИВЛ на 6 коек, а для ОРИТ для больных острым нарушением мозгового кровообращения необходимо обеспечить дыхательной аппаратурой 3 реанимационные койки. Все это в условиях перепрофилирования создает дефицит аппаратуры для проведения ИВЛ и неинвазивной вентиляции легких (НИВЛ).

Целью нашего исследования является расчет потребности стационара, перепрофилированного для лечения пациентов инфекционного профиля, в реанимационных койках и аппаратах для проведения ИВЛ и НИВЛ.

\section{Материалы и методы}

Проведен анализ работы Городской клинической больницы № 15 им. О.М. Филатова в условиях перепрофилирования под лечение пациентов инфекционного профиля за период с 03.04.2020 по 12.05.2020 при соблюдении требований действующих нормативных актов с учетом характера и особенностей течения новой коронавирусной инфекции COVID-19, осложненной внебольничной пневмонией, в сравнении с аналогичным периодом работы в условиях скоропомощного многопрофильного стационара. В условиях перепрофилирования увеличился коечный фонд больницы с 1186 до 1610, количество реанимационных «взрослых» коек возросло со 105 до 130. В условиях коронавирусной инфекции показанием к госпитализации в стационар является среднетяжелое и тяжелое течение заболевания при наличии дыхательных расстройств на фоне пневмонии, интоксикации. В случае увеличивающегося потока поступающих пациентов в ОРИТ имеется возможность увеличения коечного фонда отделений реанимации на 30 \% от штатного количества без ущерба оснащенности реанимационных коек необходимым оборудованием. Показанием для лечения в условиях ОРИТ являлась необходимость проведения мероприятий интенсивной терапии пациенту с коронавирусной инфекцией и внебольничной пневмонией при оценке состояния пациента по шкале NEWS в 6-7 баллов и более, а также нарушение витальных функций организма. Показаниями для проведения ИВЛ пациентам считали наличие дыхательной недостаточности, неустранимой другими методами (инсуффляцией увлажненного кислорода, высокопо- 


\section{ИНТЕНСИВНАЯ ТЕРАПИЯ НОВОЙ КОРОНАВИРУСНОЙ ИНФЕКЦИИ СОVID-19}

точной назальной оксигенацией, НИВЛ в том числе), при развитии гипоксемии и гипоксии. Лечение пациентов в ОРИТ осуществлялось в соответствии с действующими клиническими рекомендациями по лечению новой коронавирусной инфекции COVID-19 и стандартами оказания медицинской помощи.

Некоторые статистические данные за период работы в условиях инфекционного госпиталя представлены в табл. 1.

\section{Таблица 1. Показатели работы инфекционного стационара и востребованность дыхательной аппаратуры \\ Table 1. Indicators of functioning of infectious diseases hospital and requirement of respiratory machines}

\begin{tabular}{|c|c|c|c|c|c|c|c|c|c|}
\hline \multirow[b]{2}{*}{ Дата } & \multirow{2}{*}{$\begin{array}{c}\text { Всего пациен- } \\
\text { тов в стацио- } \\
\text { наре }\end{array}$} & \multicolumn{2}{|c|}{ Пациентов в ОРИТ } & \multicolumn{2}{|c|}{$\begin{array}{c}\text { Пациентов } \\
\text { на НИвл }\end{array}$} & \multicolumn{2}{|c|}{ Пациентов на ИВЛ } & \multicolumn{2}{|c|}{$\begin{array}{c}\text { Задействованные в ра- } \\
\text { боте аппараты ИвЛ }\end{array}$} \\
\hline & & A6c. & $\begin{array}{c}\text { \% к общему } \\
\text { числу больных } \\
\text { в стационаре }\end{array}$ & A6c. & $\begin{array}{l}\text { \% к общему } \\
\text { числу боль- } \\
\text { ных в ОРИт }\end{array}$ & Aбc. & $\begin{array}{l}\text { \% к общему } \\
\text { числу боль- } \\
\text { ных в ОРИт }\end{array}$ & Aбc. & $\begin{array}{c}\% \text { к обще- } \\
\text { му числу } \\
\text { коек ОРИт }\end{array}$ \\
\hline 3.04 .20 & 774 & 70 & 9,04 & 4 & 42,86 & 30 & 42,86 & 34 & 26,15 \\
\hline 4.04 .20 & 868 & 73 & 8,41 & 5 & 47,95 & 35 & 47,95 & 40 & 30,77 \\
\hline 5.04 .20 & 1221 & 101 & 8,27 & 2 & 41,58 & 42 & 41,58 & 44 & 33,85 \\
\hline 6.04 .20 & 1262 & 86 & 6,81 & 1 & 48,84 & 42 & 48,84 & 43 & 33,08 \\
\hline 7.04 .20 & 1301 & 92 & 7,07 & 2 & 46,74 & 43 & 46,74 & 45 & 34,62 \\
\hline 8.04 .20 & 1449 & 102 & 7,04 & 3 & 46,08 & 47 & 46,08 & 50 & 38,46 \\
\hline 9.04 .20 & 1415 & 100 & 7,07 & 2 & 55,00 & 55 & 55,00 & 57 & 43,85 \\
\hline 10.04 .20 & 1536 & 120 & 7,81 & 4 & 50,00 & 60 & 50,00 & 64 & 49,23 \\
\hline 11.04 .20 & 1509 & 126 & 8,35 & 5 & 51,59 & 65 & 51,59 & 70 & 53,85 \\
\hline 12.04 .20 & 1534 & 135 & 8,80 & 2 & 47,41 & 64 & 47,41 & 66 & 50,77 \\
\hline 13.04 .20 & 1542 & 133 & 8,63 & 1 & 50,38 & 67 & 50,38 & 68 & 52,31 \\
\hline 14.04 .20 & 1533 & 134 & 8,74 & 2 & 50,00 & 67 & 50,00 & 69 & 53,08 \\
\hline 15.04 .20 & 1497 & 130 & 8,68 & 4 & 56,15 & 73 & 56,15 & 77 & 59,23 \\
\hline 16.04 .20 & 1492 & 126 & 8,45 & 2 & 52,38 & 66 & 52,38 & 68 & 52,31 \\
\hline 17.04 .20 & 1487 & 122 & 8,20 & 4 & 59,02 & 72 & 59,02 & 76 & 58,46 \\
\hline 18.04 .20 & 1440 & 133 & 9,24 & 5 & 58,65 & 78 & 58,65 & 83 & 63,85 \\
\hline 19.04 .20 & 1485 & 144 & 9,70 & 2 & 50,69 & 73 & 50,69 & 75 & 57,69 \\
\hline 20.04 .20 & 1598 & 145 & 9,07 & 1 & 48,28 & 70 & 48,28 & 71 & 54,62 \\
\hline 21.04 .20 & 1569 & 147 & 9,37 & 2 & 55,78 & 82 & 55,78 & 84 & 64,62 \\
\hline 22.04 .20 & 1617 & 141 & 8,72 & 3 & 55,32 & 78 & 55,32 & 81 & 62,31 \\
\hline 23.04 .20 & 1578 & 151 & 9,57 & 2 & 53,64 & 81 & 53,64 & 83 & 63,85 \\
\hline 24.04 .20 & 1540 & 148 & 9,61 & 4 & 54,05 & 80 & 54,05 & 84 & 64,62 \\
\hline 25.04 .20 & 1525 & 154 & 10,10 & 5 & 51,30 & 79 & 51,30 & 84 & 64,62 \\
\hline 26.04 .20 & 1541 & 161 & 10,45 & 2 & 52,80 & 85 & 52,80 & 87 & 66,92 \\
\hline 27.04 .20 & 1607 & 161 & 10,02 & 1 & 52,80 & 85 & 52,80 & 86 & 66,15 \\
\hline 28.04 .20 & 1608 & 170 & 10,57 & 2 & 53,53 & 91 & 53,53 & 93 & 71,54 \\
\hline 29.04 .20 & 1483 & 161 & 10,86 & 4 & 57,14 & 92 & 57,14 & 96 & 73,85 \\
\hline 30.04 .20 & 1364 & 150 & 11,00 & 2 & 56,67 & 85 & 56,67 & 87 & 66,92 \\
\hline 1.05 .20 & 1315 & 150 & 11,41 & 4 & 55,33 & 83 & 55,33 & 87 & 66,92 \\
\hline
\end{tabular}




\begin{tabular}{|c|c|c|c|c|c|c|c|c|c|}
\hline \multirow[b]{2}{*}{ Дата } & \multirow{2}{*}{$\begin{array}{c}\text { Всего пациен- } \\
\text { тов в стацио- } \\
\text { наре }\end{array}$} & \multicolumn{2}{|c|}{ Пациентов в ОРИТ } & \multicolumn{2}{|c|}{$\begin{array}{c}\text { Пациентов } \\
\text { на НИВл }\end{array}$} & \multicolumn{2}{|c|}{ Пациентов на ИВЛ } & \multicolumn{2}{|c|}{$\begin{array}{c}\text { Задействованные в ра- } \\
\text { боте аппараты ИВЛ }\end{array}$} \\
\hline & & A6c. & $\begin{array}{c}\text { \% к общему } \\
\text { числу больных } \\
\text { в стационаре }\end{array}$ & A6c. & $\begin{array}{l}\text { \% к общему } \\
\text { числу боль- } \\
\text { ных в ОРИТ }\end{array}$ & Aбc. & $\begin{array}{l}\text { \% к общему } \\
\text { числу боль- } \\
\text { ных в ОРИт }\end{array}$ & Aбc. & $\begin{array}{c}\% \text { к обще- } \\
\text { му числу } \\
\text { коек ОРИТ }\end{array}$ \\
\hline 2.05 .20 & 1337 & 160 & 11,97 & 5 & 53,13 & 85 & 53,13 & 90 & 69,23 \\
\hline 3.05 .20 & 1357 & 160 & 11,79 & 2 & 48,75 & 78 & 48,75 & 80 & 61,54 \\
\hline 4.05 .20 & 1404 & 160 & 11,40 & 1 & 43,13 & 69 & 43,13 & 70 & 53,85 \\
\hline 5.05 .20 & 1358 & 152 & 11,19 & 2 & 44,74 & 68 & 44,74 & 70 & 53,85 \\
\hline 6.05 .20 & 1377 & 161 & 11,69 & 5 & 44,72 & 72 & 44,72 & 77 & 59,23 \\
\hline 7.05 .20 & 1331 & 159 & 11,95 & 2 & 41,51 & 66 & 41,51 & 68 & 52,31 \\
\hline 8.05 .20 & 1333 & 150 & 11,25 & 4 & 46,00 & 69 & 46,00 & 73 & 56,15 \\
\hline 9.05 .20 & 1299 & 160 & 12,32 & 5 & 37,50 & 60 & 37,50 & 65 & 50,00 \\
\hline 10.05 .20 & 1348 & 166 & 12,31 & 2 & 36,75 & 61 & 36,75 & 63 & 48,46 \\
\hline 11.05 .20 & 1343 & 149 & 11,09 & 1 & 38,93 & 58 & 38,93 & 59 & 45,38 \\
\hline 12.05 .20 & 1340 & 157 & 11,72 & 2 & 40,76 & 64 & 40,76 & 66 & 50,77 \\
\hline$M \pm \sigma$ & $1412,9 \pm 174,9$ & $137,5 \pm 26,2$ & & & & $68 \pm 15,1$ & & $70,8 \pm 15$ & \\
\hline
\end{tabular}

Из представленных данных следует, что востребованность реанимационной койки при лечении пациентов с коронавирусной инфекцией и внебольничной пневмонией составляет как минимум $12 \%$ от общего количества госпитальных коек при условии обеспеченности кислородной подводкой госпитальных отделений не менее чем на $70 \%$ от общего числа коек, что является одним из основных требований к организации работы госпитальных отделений.

С другой стороны, представленные данные относительно востребованности аппаратуры для проведения ИВЛ и НИВЛ говорят о том, что минимум $65 \%$ коечного реанимационного фонда должно быть оснащено аппаратами ИВЛ, а с учетом необходимости расширения коечного фонда отделений реанимации в условиях увеличенной нагрузки на них и возможного массового поступления пациентов минимально необходимое количество аппаратов ИВЛ возрастает до 80 \% от заявленной мощности реанимационных отделений.
Для сравнения проведен анализ тех же показателей, но в условиях работы скоропомощного многопрофильного стационара (табл. 2). В состав анестезиолого-реанимационной службы многопрофильного скоропомощного стационара входило 9 отделений анестезиологии-реанимации для взрослых общей численностью коек -105 . Отделения имели профильность, которая была обусловлена наличием в составе больницы кардиохирургии, травматологии, гинекологии и других хирургических отделений, регионарного сосудистого центра, диализного центра и т. д., и были оснащены в соответствии с Приказами Минздрава РФ № 919н, 918н, 928н. Из данных табл. 2 следует, что стандартное оснащение реанимационных отделений полностью обеспечивает потребность в аппаратах ИВЛ. В условиях работы скоропомощного многопрофильного стационара при полной загрузке отделений, при полной штатной комплектации ОРИТ одномоментно в среднем задействовано около 50 \% аппаратов ИВЛ даже при условии работы с перегрузом по больным. 


\section{ИНТЕНСИВНАЯ ТЕРАПИЯ НОВОЙ КОРОНАВИРУСНОЙ ИНФЕКЦИИ СОVID-19}

Таблица 2. Показатели работы скоропомощного многопрофильного стационара и востребованность дыхательной аппаратуры

Table 2. Indicators of functioning of urgent multiprofile hospital and requirement of respiratory machines

\begin{tabular}{|c|c|c|c|c|c|c|c|c|c|}
\hline \multirow[b]{2}{*}{ Дата } & \multirow{2}{*}{$\begin{array}{c}\text { Всего пациен- } \\
\text { тов в стацио- } \\
\text { наре }\end{array}$} & \multicolumn{2}{|c|}{ Пациентов в ОРИТ } & \multicolumn{2}{|c|}{$\begin{array}{c}\text { Пациентов } \\
\text { на НИВл }\end{array}$} & \multicolumn{2}{|c|}{ Пациентов на Ивл } & \multicolumn{2}{|c|}{$\begin{array}{c}\text { Задействованные в ра- } \\
\text { боте аппараты ИВЛ }\end{array}$} \\
\hline & & A6c. & $\begin{array}{c}\text { \% к общему } \\
\text { числу боль- } \\
\text { ных в стацио- } \\
\text { наре }\end{array}$ & Aбc. & $\begin{array}{c}\text { \% к обще- } \\
\text { му числу } \\
\text { больных } \\
\text { в ОРИТ }\end{array}$ & Aбc. & $\begin{array}{c}\text { \% к обще- } \\
\text { му числу } \\
\text { больных } \\
\text { в ОРИт }\end{array}$ & A6c. & $\begin{array}{c}\text { \% к обще- } \\
\text { му числу } \\
\text { коек ОРИТ }\end{array}$ \\
\hline 1 & 2 & 3 & 4 & 5 & 6 & 7 & 8 & 9 & 10 \\
\hline 3.04.19 & 1459 & 116 & 9,78 & 0 & 0,00 & 44 & 37,93 & 44 & 41,90 \\
\hline 4.04.19 & 1497 & 123 & 10,37 & 0 & 0,00 & 50 & 40,65 & 50 & 47,62 \\
\hline 5.04 .19 & 1263 & 117 & 9,87 & 3 & 2,56 & 52 & 44,44 & 55 & 52,38 \\
\hline 6.04 .19 & 1458 & 115 & 9,70 & 1 & 0,87 & 48 & 41,74 & 49 & 46,67 \\
\hline 7.04.19 & 1317 & 117 & 9,87 & 4 & 3,42 & 54 & 46,15 & 58 & 55,24 \\
\hline 8.04 .19 & 1389 & 125 & 10,54 & 2 & 1,60 & 56 & 44,80 & 58 & 55,24 \\
\hline 9.04 .19 & 1461 & 135 & 11,38 & 1 & 0,74 & 59 & 43,70 & 60 & 57,14 \\
\hline 10.04 .19 & 1072 & 111 & 9,36 & 2 & 1,80 & 44 & 39,64 & 46 & 43,81 \\
\hline 11.04 .19 & 1031 & 111 & 9,36 & 1 & 0,90 & 47 & 42,34 & 48 & 45,71 \\
\hline 12.04 .19 & 1474 & 136 & 11,47 & 2 & 1,47 & 57 & 41,91 & 59 & 56,19 \\
\hline 13.04 .19 & 982 & 118 & 9,95 & 2 & 1,69 & 49 & 41,53 & 51 & 48,57 \\
\hline 14.04 .19 & 1063 & 120 & 10,12 & 3 & 2,50 & 40 & 33,33 & 43 & 40,95 \\
\hline 15.04 .19 & 1485 & 123 & 10,37 & 3 & 2,44 & 44 & 35,77 & 47 & 44,76 \\
\hline 16.04 .19 & 1445 & 119 & 10,03 & 1 & 0,84 & 50 & 42,02 & 51 & 48,57 \\
\hline 17.04 .19 & 1286 & 121 & 10,20 & 1 & 0,83 & 51 & 42,15 & 52 & 49,52 \\
\hline 18.04 .19 & 1270 & 120 & 10,12 & 1 & 0,83 & 55 & 45,83 & 56 & 53,33 \\
\hline 19.04 .19 & 1301 & 120 & 10,12 & 0 & 0,00 & 49 & 40,83 & 49 & 46,67 \\
\hline 20.04 .19 & 1456 & 117 & 9,87 & 4 & 3,42 & 46 & 39,32 & 50 & 47,62 \\
\hline 21.04 .19 & 1094 & 121 & 10,20 & 2 & 1,65 & 48 & 39,67 & 50 & 47,62 \\
\hline 22.04 .19 & 1090 & 127 & 10,71 & 2 & 1,57 & 49 & 38,58 & 51 & 48,57 \\
\hline 23.04 .19 & 1257 & 116 & 9,78 & 1 & 0,86 & 49 & 42,24 & 50 & 47,62 \\
\hline 24.04 .19 & 1235 & 112 & 9,44 & 2 & 1,79 & 51 & 45,54 & 53 & 50,48 \\
\hline 25.04 .19 & 1441 & 128 & 10,79 & 0 & 0,00 & 51 & 39,84 & 51 & 48,57 \\
\hline 26.04 .19 & 1446 & 122 & 10,29 & 0 & 0,00 & 51 & 41,80 & 51 & 48,57 \\
\hline 27.04 .19 & 1384 & 110 & 9,27 & 0 & 0,00 & 46 & 41,82 & 46 & 43,81 \\
\hline 28.04 .19 & 1184 & 125 & 10,54 & 1 & 0,80 & 55 & 44,00 & 56 & 53,33 \\
\hline 29.04 .19 & 1098 & 117 & 9,87 & 3 & 2,56 & 41 & 35,04 & 44 & 41,90 \\
\hline 30.04 .19 & 1352 & 131 & 11,05 & 1 & 0,76 & 54 & 41,22 & 55 & 52,38 \\
\hline 1.05 .19 & 1393 & 124 & 10,46 & 2 & 1,61 & 50 & 40,32 & 52 & 49,52 \\
\hline
\end{tabular}




\begin{tabular}{|c|c|c|c|c|c|c|c|c|c|}
\hline \multirow[b]{2}{*}{ Дата } & \multirow{2}{*}{$\begin{array}{c}\text { Всего пациен- } \\
\text { тов в стацио- } \\
\text { наре }\end{array}$} & \multicolumn{2}{|c|}{ Пациентов в ОРИТ } & \multicolumn{2}{|c|}{$\begin{array}{c}\text { Пациентов } \\
\text { на НИвл }\end{array}$} & \multicolumn{2}{|c|}{ Пациентов на ИВЛ } & \multicolumn{2}{|c|}{$\begin{array}{c}\text { Задействованные в ра- } \\
\text { боте аппараты ИВЛ }\end{array}$} \\
\hline & & Aбc. & $\begin{array}{c}\text { \% к общему } \\
\text { числу боль- } \\
\text { ных в стацио- } \\
\text { наре }\end{array}$ & A6c. & $\begin{array}{l}\text { \% к обще- } \\
\text { му числу } \\
\text { больных } \\
\text { в ОРИт }\end{array}$ & A6c. & $\begin{array}{c}\text { \% к обще- } \\
\text { му числу } \\
\text { больных } \\
\text { в ОРИт }\end{array}$ & A6c. & $\begin{array}{c}\text { \% к обще- } \\
\text { му числу } \\
\text { коек ОРИт }\end{array}$ \\
\hline 1 & 2 & 3 & 4 & 5 & 6 & 7 & 8 & 9 & 10 \\
\hline 2.05.19 & 1438 & 128 & 10,79 & 2 & 1,56 & 54 & 42,19 & 56 & 53,33 \\
\hline 3.05.19 & 1374 & 111 & 9,36 & 1 & 0,90 & 43 & 38,74 & 44 & 41,90 \\
\hline 4.05.19 & 1408 & 121 & 10,20 & 3 & 2,48 & 46 & 38,02 & 49 & 46,67 \\
\hline 5.05 .19 & 1274 & 129 & 10,88 & 2 & 1,55 & 49 & 37,98 & 51 & 48,57 \\
\hline 6.05 .19 & 1209 & 113 & 9,53 & 0 & 0,00 & 44 & 38,94 & 44 & 41,90 \\
\hline 7.05.19 & 1016 & 117 & 9,87 & 1 & 0,85 & 46 & 39,32 & 47 & 44,76 \\
\hline 8.05 .19 & 1382 & 125 & 10,54 & 0 & 0,00 & 47 & 37,60 & 47 & 44,76 \\
\hline 9.05 .19 & 1292 & 116 & 9,78 & 2 & 1,72 & 52 & 44,83 & 54 & 51,43 \\
\hline 10.05 .19 & 1052 & 109 & 9,19 & 2 & 1,83 & 44 & 40,37 & 46 & 43,81 \\
\hline 11.05 .19 & 1251 & 113 & 9,53 & 1 & 0,88 & 45 & 39,82 & 46 & 43,81 \\
\hline 12.05 .19 & 1352 & 127 & 10,71 & 2 & 1,57 & 50 & 39,37 & 52 & 49,52 \\
\hline$M \pm \sigma$ & $1293,3 \pm 153,6$ & $120,1 \pm 6,7$ & & & & $49 \pm 4,4$ & & $50,5 \pm 4$ & \\
\hline
\end{tabular}

Таким образом, в условиях лечения пациентов с новой коронавирусной инфекцией COVID-19 с учетом характера заболевания и его течения значимо возрастает потребность в проведении НИВЛ и ИВЛ, что требует большего количества оборудования для их обеспечения.

\section{Результаты и обсуждение}

Полученные данные, представленные в табл. 1, свидетельствуют о том, что с учетом особенностей и тяжести течения НКИ COVID-19 обеспеченность реанимационными койками должна составлять не менее 12 \% от общего коечного фонда больницы.

В составе многопрофильного стационара для оказания специализированной медицинской помощи, как правило, в настоящее время функционируют несколько ОРИТ, имеющих различную профильность: отделения реанимации для больных острым инфарктом миокарда и/или для больных острым нарушением мозгового кровообращения. Оснащение таких отделений коренным образом отличается от таковых общего и хирургического профиля, которые на 100 \% коечного фонда оснащены аппаратурой для проведения ИВЛ. Так, для ОРИТ для больных острым инфарктом миокарда, согласно Приказу Минздрава РФ № 918н от 15.12.2012 необходимо оснащение аппаратурой из расчета 1 аппарат ИВЛ на 6 ре- анимационных коек, а для ОРИТ для больных острым нарушением мозгового кровообращения, согласно Приказу Минздрава РФ № 928н от 15.11.2012 необходимо располагать парком машин из расчета 1 аппарат ИВЛ на 3 реанимационные койки. Все это создает предпосылки для нехватки аппаратов ИВЛ в инфекционном госпитале и приводит к тому, что на момент принятия решения о перепрофилировании стационара для оказания помощи пациентам с новой коронавирусной инфекцией COVID-19 имеется дефицит парка аппаратов ИВЛ. Сложившаяся ситуация требует немедленных ответных мер и административных решений - от перераспределения аппаратов ИВЛ внутри перепрофилированного стационара, организации экстренного приобретения аппаратов, вплоть до рассмотрения возможности применения наркозно-дыхательной аппаратуры для проведения НИВЛ и ИВЛ пациентам.

Принимая во внимание частоту и тяжесть поражения дыхательной системы при пневмонии, вызванной COVID-19, а также в связи с этим потребность в применении аппаратов ИВЛ, минимально необходимое количество аппаратов ИВЛ на 130 коек должно составлять 96. Таким образом, для минимально необходимого обеспечения работы ОРИТ требуется оснастить аппаратами ИВЛ не менее 75 \% реанимационных коек.

Учитывая необходимость наличия резервной аппаратуры для ИВЛ в случае возможного выхода из строя аппаратов, а также возможной перегруженности ОРИТ, 
обеспеченность аппаратами ИВЛ должна составлять не менее $80 \%$.

\section{Выводы}

1. В условиях работы стационара, ориентированного на лечение пациентов НКИ COVID-19, необходимо развертывание коек реанимационного профиля с оборудованием каждой реанимационной койки аппаратурой для проведения НИВЛ и ИВЛ.

2. Минимально необходимое количество коек реанимационного профиля, исходя из наших данных, должно составлять не менее 12 \% от общего коечного фонда больницы.

3. При развертывании ОРИТ необходимо предусмотреть возможность дополнительного расширения коечного фонда в случае необходимости до $30 \%$ от числа реанимационных коек.

4. Для обеспечения бесперебойной работы реанимационной службы необходимо оснащение не ме- нее 80 \% коек аппаратурой для проведения НИВЛ и ИВЛ.

Конфликт интересов. Авторы заявляют об отсутствии конфликта интересов.

Вклад авторов. Силаев Б.В., Вечорко В.И., Проценко Д.Н. - научное руководство, разработка концепции статьи, получение и анализ фактических данных, написание и редактирование текста статьи, проверка и утверждение текста статьи; Аверков О.В., Е.Ю. Халикова - разработка концепции статьи, набор и обработка материала, получение и анализ фактических данных, написание и редактирование текста статьи, проверка и утверждение текста статьи.

\section{ORCID авторов}

Силаев Б.В. - 0000-0002-9698-3915

Вечорко В.И. - 0000-0003-3568-5065

Проценко Д.Н. - 0000-0002-5166-3280

Аверков О.В. - 0000-0002-1839-4592

Халикова Е.Ю. - 0000-0001-8661-9418

\section{Литература/References}

[1] Временные методические рекомендации. «Профилактика, диагностика и лечение новой коронавирусной инфекции COVID-19». 6-я версия от 28.04.2020. Режим доступа: http://nasci.ru/?id = 11052. Ссылка активна на 1 июня 2020 г. [Vremennye metodicheskie rekomendacii. "Profilaktika, diagnostika i lechenie novoj koronavirusnoj infekcii COVID-19", 6 versiya ot 28.04.2020. Available at: http://nasci.ru/?id $=11052$. Accessed: 1 june 2020. (In Russ)]

[2] «M.P. 3.1.0170-20.3.1. Профилактика инфекционных болезней. Эпидемиология и профилактика COVID-19. Методические рекомендации». (Утв. Главным государственным санитарным врачом РФ 30.03.2020), 15.04.2020. Режим доступа: https:// base.garant.ru/73864250/. Ссылка активна на 1 июня 2020 года. ["M.R. 3.1.0170-20.3.1. Profilaktika infekcionnyh boleznej. Epidemiologiya i profilaktika COVID-19. Metodicheskie rekomendacii" (Utv. Glavnym gosudarstvennym sanitarnym vrachom RF 30.03.2020), 15.04.2020. Available at: https://base. garant.ru/73864250/. Accessed: 1 jun 2020. (In Russ)]

[3] Приказ Министерства здравоохранения РФ от 15 ноября 2012 г. № 928н «Об утверждении Порядка оказания медицинской помощи больным с острыми нарушениями мозгового кровообращения». Режим доступа: https://base. garant.ru/70334856/. Ссылка активна на 1 июня 2020 г. [Prikaz Ministerstva zdravoohraneniya RF ot 15 noyabrya 2012 g. \# 918n
"Ob utverzhdenii Poryadka okazaniya medicinskoj pomoshchi bol'nym s serdechno-sosudistymi zabolevaniyami". Available at: https://base.garant.ru/70299174/. Accessed: 1 jun 2020. (In Russ)]

[4] Приказ Министерства здравоохранения РФ от 15 ноября 2012 г. № 918н «Об утверждении Порядка оказания медицинской помощи больным с сердечно-сосудистыми заболеваниями». Режим доступа: https://base.garant.ru/70299174/. Ссылка активна на 1 июня 2020. [Prikaz Ministerstva zdravoohraneniya RF ot 15 noyabrya 2012 g. \# 918n "Ob utverzhdenii Poryadka okazaniya medicinskoj pomoshchi bol'nym s serdechnososudistymi zabolevaniyami". Available at: https://base.garant. ru/70299174/. Accessed: 1 jun 2020. (In Russ)]

[5] Приказ Министерства здравоохранения РФ от 15 ноября 2012 г. № 919н «О6 утверждении Порядка оказания медицинской помощи взрослому населению по профилю «анестезиология и реаниматология» (с изменениями и дополнениями). Режим доступа: https://base.garant.ru/70301502/. Ссылка активна на 1 июня 2020 г. [Prikaz Ministerstva zdravoohraneniya RF ot 15 noyabrya 2012 g. \# 919n "Ob utverzhdenii Poryadka okazaniya medicinskoj pomoshchi vzroslomu naseleniyu po profilyu «anesteziologiya i reanimatologiya" (s izmeneniyami i dopolneniyami). Available at: https://base.garant.ru/70301502/. Accessed: 1 jun 2020. (In Russ)] 